\title{
Relação materno infantil e o desenvolvimento da criança
}

\author{
Maternal child relationship and child development \\ Relación materno-infantil y desarrollo infantil
}

Recebido: 20/02/2021 | Revisado: 01/03/2021 | Aceito: 12/03/2021 | Publicado: 19/03/2021

Thainá da Silva Cabral

ORCID: https://orcid.org/0000-0002-6972-2904 Universidade Federal de Alagoas, Brasil E-mail: thainacabral.cabral@gmail.com

Rafael da Silva Bezerra

ORCID: https://orcid.org/0000-0003-1393-717X Universidade Federal de Alagoas, Brasil

E-mail: bezerrarafaelrb@gmail.com

Keila Cristina Pereira do Nascimento Oliveira

ORCID: https://orcid.org/0000-0003-0167-5889 Universidade Federal de Alagoas, Brasil

E-mail: keila.oliveira@eenf.ufal.br

Ana Carolina Santana Vieira

ORCID: https://orcid.org/0000-0002-7273-1414 Universidade Federal de Alagoas, Brasil

E-mail: ana.vieira@eenf.ufal.br

Fernanda Demutti Pimpão Martins

ORCID: https://orcid.org/0000-0002-6821-641X

Universidade Federal do Rio Grande, Brasil.

E-mail: fhernandapimpao@yahoo.com.br

Vanessa Vieira de Souza Oliveira

ORCID: https://orcid.org/0000-0001-7341-0615

Universidade Federal de Alagoas, Brasil

E-mail: vanessavso25@gmail.com

Roberto da Silva Bezerra

ORCID: https://orcid.org/0000-0001-7625-075X

Centro Universitário Maurício de Nassau, Brasil

E-mail: betobezerra21@gmail.com

Marcela Cristina dos Santos Barros

ORCID: https://orcid.org/0000-0001-7863-145X Universidade Federal de Alagoas, Brasil E-mail: mh0673@gmail.com

Daniella Marques dos Santos Mariano

ORCID: https://orcid.org/0000-0001-8977-4149

Universidade Federal de Alagoas, Brasil

E-mail: quirimarques@hotmail.com

\begin{abstract}
Resumo
Objetivo: Analisar o vínculo materno infantil de mulheres atendidas em uma Unidade Básica de Saúde. Metodologia: Trata-se de um estudo do tipo descritivo, transversal, exploratório, com abordagem qualitativa, realizado com 20 mães de crianças de até 1 ano de idade da área de abrangência da Unidade de Saúde da Família Robson Cavalcante, localizada em Maceió/AL. A pesquisa foi realizada através da realização de uma entrevista semiestruturada sobre o laço mãe e bebê e os dados foram tratados através da análise de conteúdo baseada na proposta de Laurence Bardin. Resultados: A idade materna variou entre 14 e 35 anos, sendo 6 adolescentes. As falas das mães em relação às mudanças através da gestação envolveram, predominantemente, o âmbito pessoal quanto ao amadurecimento materno. De modo geral, sobre a importância do vínculo, as mães acham importante a relação com o bebê para a construção da personalidade da criança e para o reconhecimento quando atingirem a fase adulta. Conclusão: Portanto, percebe-se que os estímulos que influenciam no crescimento e no desenvolvimento da criança são multifatoriais, destacando-se o planejamento da gestação, o estado emocional e psicológico materno, a sensibilidade da mãe, a sobrecarga materna entre outros.
\end{abstract}

Palavras-chave: Crescimento e desenvolvimento; Comportamento materno; Relações mãe-filho; Saúde da criança.

\section{Abstract}

Objective: To analyze the maternal and child bond of women assisted in a Basic Health Unit. Methodology: This is a descriptive, cross-sectional, exploratory study with a qualitative approach, carried out with 20 mothers of children up to 1 year old in the coverage area of the Family Health Unit Robson Cavalcante, located in Maceió / AL .The research was conducted through a semi-structured interview about the mother and baby bond and the data were processed through 
content analysis based on Laurence Bardin's proposal. Results: Maternal age ranged from 14 to 35 years, of which 6 were adolescents. The mothers' statements regarding changes through pregnancy predominantly involved the personal scope regarding maternal maturation. In general, on the importance of the bond, mothers find the relationship with the baby important for the construction of the child's personality and for recognition when they reach adulthood. Conclusion: Therefore, it is perceived that the stimuli that influence the child's growth and development are multifactorial, highlighting the planning of pregnancy, the maternal emotional and psychological state, the sensitivity of the mother, maternal overload, among others.

Keywords: Growth and development; Maternal behavior; Mother-child relationships; Child health.

\section{Resumen}

Objetivo: Analizar el vínculo materno-infantil de mujeres atendidas en una Unidad Básica de Salud. Metodología: Estudio descriptivo, transversal, exploratorio con abordaje cualitativo, realizado con 20 madres de niños hasta 1 año de edad en el Ámbito de alcance de la Unidad de Salud de la Familia Robson Cavalcante, ubicada en Maceió / AL. Se llevó a cabo a través de una entrevista semiestructurada sobre el vínculo madre-bebé y los datos fueron procesados a través del análisis de contenido basado en la propuesta de Laurence Bardin. Resultados: La edad materna osciló entre 14 y 35 años, de los cuales 6 eran adolescentes. Los discursos de las madres sobre los cambios durante el embarazo involucraron predominantemente el ámbito personal en cuanto a la maduración materna. En general, en cuanto a la importancia del vínculo, las madres consideran importante la relación con el bebé para la construcción de la personalidad del niño y para el reconocimiento cuando éste llega a la edad adulta. Conclusión: Por lo tanto, es claro que los estímulos que influyen en el crecimiento y desarrollo del niño son multifactoriales, con énfasis en la planificación del embarazo, estado emocional y psicológico materno, sensibilidad materna, sobrecarga materna, entre otros.

Palabras clave: Crecimiento y desarrollo; Comportamiento materno; Relaciones madre-hijo; Salud infantil.

\section{Introdução}

O crescimento e o desenvolvimento (CD) consistem em Indicadores de Saúde da Criança essenciais para o acompanhamento e rastreamento de riscos à saúde infantil, bem como o acompanhamento da evolução saudável e da aquisição de novas habilidades, promovendo intervenções precoces e prevenindo danos futuros (Gaíva et al., 2018).

O crescimento está agregado aos fatores intrínsecos (genéticos) e extrínsecos (ambientais), sendo estes os cuidados necessários à criança, o ambiente em que a mesma está inserida, a promoção da saúde e condições de higiene, podendo colaborar ou prejudicar o crescimento saudável. Já o seu desenvolvimento é um processo dinâmico que abrange a maturação do sistema nervoso, o crescimento infantil, os aspectos psicossociais e a construção do vínculo (Almeida et al., 2017; Brasil, 2012).

Considerando a multiplicidade de aspectos relevantes para o CD é importante destacar o investimento nas relações afetivas voltadas ao bebê, que proporciona a base para o seu desenvolvimento, tendo em vista que ao nascer o neonato é totalmente dependente de alguém que seja capaz de suprir as suas demandas à medida em que o mesmo se desenvolve e tornase capaz de se autorregular. Para um desenvolvimento satisfatório são necessários investimentos através dos estímulos que são emitidos na criança. Aspectos ambientais, econômicos, sociais e biológicos influenciam no crescimento e no desenvolvimento infantil de modo positivo ou negativo, tais como as condições de vulnerabilidades sociais. Além disso, os laços iniciais do bebê, especialmente com a mãe, fundamentam a maturação psíquica, afetiva, comportamental, cognitiva e física, podendo representar um fator de risco quando não é estabelecido entre a mãe e o bebê (Brasil, 2018; Lima et al., 2016; Marciano \& Amaral, 2015; Neves et al., 2016).

Considerando as mudanças ocorridas ao longo da história cabe ressaltar as transformações na composição familiar, em que o modelo tradicional de família se amplia e passa a contemplar o modelo contemporâneo com as famílias monoparentais, pluriparentais ou recompostas (resultado de divórcios e separações) e homoafetivas que formam famílias seja pela inserção de filhos oriundos de um relacionamento heterossexual anterior, através da reprodução assistida ou ainda pelo processo de adoção (Ribeiro et al., 2017; Rosa et al., 2016).

O laço que une a mãe ao seu bebê não é predeterminado, instintivo e tampouco existente antes da real experiência da maternidade, por não ser transmitido geneticamente. Nesse viés, infere-se que tal elo é construído e exige investimento para que os envolvidos tornem o vínculo sadio e completo (Oliveira, 2016). O vínculo materno infantil é construído gradualmente e se 
estabelece diante da necessidade da aquisição de determinadas habilidades por parte do infante, sendo que este se comporta sob total dependência da mãe e também reage aos estímulos emitidos por ela. O progresso do vínculo exige envolvimento e investimento da díade mãe-bebê, configurando-se um processo bidirecional (Silva \& Braga, 2019).

Dentro da relação mãe e bebê não existe a complementaridade, visto que a mãe não conseguirá atender a todas as demandas sinalizadas pelo bebê. Em contrapartida, essa peculiaridade não assume um caráter inteiramente negativo, uma vez que ensina o bebê a se autorregular e lhe confere autonomia ao longo do seu desenvolvimento (Oliveira, 2016).

O primeiro ano de vida é promissor para o desenvolvimento infantil na relação do binômio mãe-bebê. Em virtude da imaturidade do bebê em autorregular seu estado emocional e fisiológico, as mães assumem o importante papel de modular as respostas ao estresse vivenciado pelo bebê, prontamente atendendo os sinais emitidos para alertar quaisquer desconfortos (Behrendt et al., 2019).

A qualidade do apego influencia na solidificação dos futuros relacionamentos que serão gerenciados pelo infante, uma vez que a partir do primeiro ano de vida o estado socioemocional adquire mais estabilidade. Diante disso, é necessário conhecer os fatores que recaem sobre a figura materna e que vão impactar no desenvolvimento infantil, para então direcionar as intervenções que irão proporcionar a construção do vínculo de forma satisfatória e saudável ao binômio (Behrendt et al., 2019).

Portanto, o objetivo deste estudo é analisar o vínculo materno infantil de mulheres atendidas em uma Unidade Básica de Saúde.

\section{Metodologia}

Trata-se de um estudo do tipo descritivo, transversal, exploratório, com abordagem qualitativa, sustentada pelo referencial teórico de Ramona Mercer pautada na teoria da consecução do papel materno. Esta teoria envolve a interação e o desenvolvimento dentro da relação que se estabelece entre a mãe e o filho, a propriedade que a mãe adquire ao cuidar e a satisfação que ela atinge diante desse processo de transição e de adaptação ao deixar o papel de filha para assumir a postura de mãe. A mãe evolui juntamente com o desenvolvimento da criança. Aliado a isso, a mulher vivencia uma maior vulnerabilidade ao passar por todo o processo inerente à maternidade, abrangendo as suas condições psicológicas, físicas e sociais (Santos et al., 2017).

A coleta de dados se deu através das visitas domiciliares e nas consultas de puericultura realizadas na Unidade de Saúde da Família (USF) Robson Cavalcante, localizada no município de Maceió, Alagoas, no período de dezembro de 2019 a março de 2020. As participantes da pesquisa foram 20 mães de crianças, com até 1 ano de idade, alfabetizadas, da área de abrangência da USF, e que aceitaram participar da pesquisa. Foram excluídas da pesquisa as mães de crianças com idade superior a 1 ano de idade e aquelas que não compareceram no período estabelecido para a coleta de dados. As mães elegíveis para o estudo apresentaram diferentes níveis instrucionais, com idades entre 14 e 35 anos, sendo mães de bebês até 12 meses completos, prematuros ou a termo e que residem com seus bebês.

Cada mãe abordada foi convidada a participar do estudo através de uma abordagem individual seguida da apresentação da proposta do estudo de maneira compreensível, selando este acordo através da assinatura do Termo de Consentimento Livre e Esclarecido (TCLE), assinado em duas vias, em conformidade ética com as Resoluções 466/12 e 510/16 do Conselho Nacional de Pesquisa.

De modo consensual, foram realizadas entrevistas em profundidade com cada participante do estudo, gravadas através do aparelho de celular com a utilização de um aplicativo para gravação de voz. A entrevista se deu mediante as perguntas semiestruturadas a respeito da relação entre a mãe e o bebê, incluindo os seguintes questionamentos: 1."Qual a sua reação à gravidez? Foi planejada ou inesperada, e como se deu o processo de aceitação?”; 2.“O que mudou através da gestação? Quais foram as expectativas em relação ao bebê?”; 3."Se sente ou se sentiu sobrecarregada ou com a necessidade de auxílio?”; 4.“Qual 
a importância da construção do vínculo?”; 5."Como se deu o processo de identificação das necessidades, principalmente através do choro?"; 6."Foi amamentado? Como foi o processo de amamentação?”.

A amostragem utilizada neste estudo foi a não probabilística por conveniência, por se tratar de uma etapa da pesquisa que ocorre a seleção dos elementos da população para compor a amostra, e que se caracteriza (pelo menos em parte) do julgamento do pesquisador ou do entrevistador no campo (Oliveira, 2001). Também foi utilizada a amostragem por saturação determinada para estabelecer ou fechar o tamanho final de uma amostra em estudo, interrompendo a captação de novos componentes (Fontanella et al., 2008), definida após a realização das entrevistas.

A análise de conteúdo baseada na proposta de Laurence Bardin foi utilizada para o tratamento dos dados qualitativos que foram processados através da transcrição das falas das participantes na íntegra em resposta à entrevista semiestruturada, utilizando o Google Docs para o armazenamento dos dados. As falas foram filtradas e destacadas conforme a relevância para a pesquisa. Na técnica metodológica de análise de conteúdo "o pesquisador busca compreender as características, estruturas ou modelos que estão por trás dos fragmentos de mensagens tornados em consideração" (Câmara, 2013, p. 182). Bardin indica três fases para essa análise: a pré-análise, exploração do material e tratamento dos resultados (Câmara, 2013).

O projeto foi aprovado pelo Comitê de Ética em Pesquisa da Universidade Federal de Alagoas (UFAL) sob o parecer de Certificado de Apresentação para Apreciação Ética CAAE 16676719.0.0000.5013, respeitando os princípios e diretrizes contidos na Resolução CNS n ${ }^{\circ}$ 466/12 e 510/16 do Conselho Nacional de Pesquisa em Saúde que envolve seres humanos.

\section{Resultados}

A entrevista semiestruturada contemplou questionamentos a respeito da relação entre mãe e bebê. As perguntas permitiram que as mães se expressassem livremente e sem a limitação da fala, por meio das respostas subjetivas e acompanhadas da observação da pesquisadora. Os resultados obtidos estão dispostos em tópicos em que cada um corresponde às perguntas da entrevista semiestruturada. A fim de assegurar a confidencialidade e preservar o binômio, as participantes foram identificadas com a abreviação de Mãe (M), por ordem consecutiva (M1 a M20) e, deste modo, a elaboração de categorias temáticas para sua interpretação.

\subsection{A reação materna após a descoberta da gravidez}

Este tópico traz uma reflexão acerca dos sentimentos maternos com a aproximação de uma nova fase na vida, em que transitam do papel de filhas e assumem o papel de mães, quer a gestação tenha sido planejada ou não. Além disso, passando por todo o processo gestacional, se houve a adesão e o devido acompanhamento, por parte da mãe, durante as consultas de pré-natal.

As falas a seguir são respostas às perguntas "A gestação foi planejada ou inesperada? Como se deu o processo de aceitação?"

"Foi planejada por causa do outro bebê que eu tinha perdido, aí eu planejei muito. Fiquei muito feliz, foi o meu momento." M1

"A gestação não foi planejada, foi uma surpresa, fiquei praticamente em pânico. Tive que esperar e ver que tinha uma vidinha em jogo.” M5

"A gestação foi inesperada. Eu não vou negar, eu chorei muito. Eu pedi muito perdão a Deus porque a gente nunca planejou ter outro. Eu chorei, chorei, depois tive que ter um tempo de adaptação. A gestação toda foi um processo de adaptação. Nos 5 meses quando eu descobri que era uma menina, me deixou mais feliz porque eu já tenho dois meninos." 
"Foi, dos dois. No primeiro mês quando eu descobri eu fiquei feliz, mas fiquei medrosa. Porque depois que a ficha cai, a gente tinha uma bebê de um ano e pouco, aí descobrir que tava grávida de novo [...]. Só quando você tá grávida é que a ficha cai. Poxa! Agora vão ser dois bebês, como é que vai ser? Então bateu aquela insegurança né, aquele medo. Mas graças a Deus foi dando tudo certo.” M9

"Não. Foi muito bom não, não vou mentir. Foi um baque, um choque bem grande pra mim, porque eu não estava esperando. Tanto é que eu vim descobrir já estava com quase seis meses. Foi um baque bem grande, pra eu aceitar foi mais de um mês. Mas depois foi tranquilo.” M13

"Foi planejada. Quando eu descobri fiquei louca, fiquei apaixonada, porque eu sempre quis, sempre quis uma menina." M14

“Não. Foi bom, melhor um filho do que uma doença." M15

"Foi horrível, me senti muito mal, porque eu não queria. Mas a pessoa sabe que não evitando vai engravidar. Foi um mês só que eu passei sem tomar injeção e engravidei. Pensei em abortar, ainda tentei, tomei chá. Quando a barriga foi crescendo fui me acostumando mais." M16

Diante das falas supracitadas é possível perceber a diferença entre a experiência da descoberta da gestação quando foi planejada e quando não foi planejada. As mães que desejavam engravidar e se prepararam para isso expressaram o sentimento satisfatório, de alcance do objetivo almejado. Por outro lado, as mães que não planejaram a gestação externaram a sensação que vivenciaram no momento da descoberta, prevalecendo o sentimento de medo, insegurança e pânico, demonstrando que o apoio familiar, social ou profissional é essencial para que a mulher consiga se adaptar ao seu novo papel de mãe. A rede de apoio emocional minimiza os riscos, principalmente psicológicos, que podem impactar na saúde materna, fetal, no vínculo entre a mãe e o bebê durante o ciclo gravídico-puerperal e até mesmo a longo prazo, gerando reflexos no CD infantil. Porém, mesmo diante da gestação não planejada, notou-se que as mães estavam criando seus filhos e, segundo as observações, não foram identificados casos de rejeição do bebê.

\subsection{As mudanças e as expectativas em relação ao bebê durante o ciclo gravídico}

Este tópico externa os sentimentos das mães durante a gestação ao passo que expectativas podem ser geradas ao longo do ciclo gravídico, tanto em relação ao bebê quanto às mudanças nos âmbitos pessoal, econômico, psicológico e emocional. Nesse viés, as participantes foram indagadas sobre "O que mudou através da gestação? Quais foram as expectativas em relação ao bebê?"

"Me mudou! Eu pensei que eu nunca ia conseguir, porque o povo dizia que era muita coisa, mas foi tudo diferente." M1

"Eu não sinto que mudou. Mas como a pessoa dá mais atenção ao mais novinho, eu sinto que eles sentem. Eu sempre converso com eles e explico pra eles que não é que eles vão ter que me pedir um beijo, um abraço, mas na correria do dia a dia eles podem me lembrar, porque às vezes a mamãe está na correria, porque às vezes não é o colinho que era deles." M7 
"Ela veio fazer diferença na minha vida, eu era muito agitada, depois dela eu mudei." M10

"Eu fiquei triste quando descobri, porque eu tinha gêmeos que ainda iam fazer dois anos, aí eu achei muito rápido né, dava muito trabalho cuidar deles dois e cuidar de outra bebezinha. Aí eu fiquei muito insegura. [...] Eu descobri que tava grávida já com quatro meses [...]. Aí como eu já tinha dois meninos pequenos eu queria muito uma menina, aí quando eu descobri que era menina foi só amor. [...] Meu esposo se aproximou mais, a questão financeira continuou a mesma coisa." M11

"Eu aprendi. Sei lá! Ser mãe. Ser mais madura, antes de tudo pensar nela. [...] Eu dizia assim: vindo com saúde é o que importa. Aí quando ela nasceu com esse probleminha (cardiopatia) eu sofri muito, aí eu pedi muito a Deus. [...] Mudou, mudou a minha rotina de vida. [...] Tô muito madura, porque eu era infantil."M14

“Eu passei a pensar mais nela do que em mim.” M17

As mudanças mencionadas pelas participantes foram predominantemente no âmbito pessoal, em relação a maturidade e a responsabilidade enquanto mãe. Quanto às expectativas durante a gestação a maioria referiu a ansiedade para a descoberta do sexo do bebê, visto que nessa fase algumas mães podem apresentar preferência para que o bebê seja do sexo feminino ou masculino. Além disso, a insegurança diante da nova fase.

\subsection{Sobrecarrega materna nas atribuições diárias}

Este item aborda as falas das mães sobre o sentimento de sobrecarga diante dos cuidados inerentes ao bebê e a rotina dentro do convívio familiar. As participantes do estudo foram questionadas da seguinte forma: "Se sente ou se sentiu sobrecarregada ou com a necessidade de auxílio?". Perante isso, foram transcritas as falas de algumas mães a seguir:

"Me sinto sobrecarregada, porque sou eu sozinha pra tudo, pra cuidar dele, da casa. Às vezes fico muito cansada, estressada. Preciso que ele fique com alguém pra eu fazer alguma coisa, porque até pra eu ir ao banheiro eu não consigo." M1

"Não me sinto sobrecarregada, ela é tranquila, calma." M2

“Tenho dificuldade de cuidar dele.” M6

"Me sinto mais sobrecarregada por conta do trabalho." M9

"Às vezes me sinto sobrecarregada. Não (necessidade de auxílio), porque eu tenho duas moças em casa e elas sempre me ajudam. E o pai quando está em casa me ajuda.” M11

A mãe pode se sentir sobrecarregada devido a responsabilidade com as atividades domésticas e a dependência do bebê para a satisfação das necessidades, como dar banho, alimentar, a troca de fraldas, consolar, colocar para dormir e entre outras. Algumas mães, mesmo tendo mais de um filho, disseram que não se sentem sobrecarregadas ou com a necessidade de ter alguém para auxiliar na execução dessas atividades. 


\subsection{A importância da construção do vínculo}

O vínculo que une a mãe ao seu bebê é construído paulatinamente, tendo início no ciclo gravídico e repercutindo por toda a vida. É um processo que exige envolvimento, cuidados, entrega, amor, dedicação e outros aspectos que alicerçam o elo materno infantil. Este tópico corresponde aos resultados obtidos em resposta à pergunta "Qual a importância da construção do vínculo?". À vista disso, seguem as falas de algumas participantes:

“Às vezes eu não sei se consigo ser uma mãe boa pra ele, eu tento ser melhor, porque minha mãe não foi uma mãe pra mim, ela vivia trabalhando e me deixava com a minha avó. [...] Eu sei como fui criada sem pai e "bem dizer" sem mãe, só por vó. Eu não quero isso pra ele, eu quero estar ali junto com ele em todo momento.” M1

"Super importante, ele praticamente depende de mim, praticamente meu coração fora do corpo.” M5

"A gente fica insegura, sem saber como vai ser, principalmente mãe de primeira viagem a gente fica muito insegura, e através das reuniões a gente vai adquirindo experiência e sabendo lidar com cada frustração, porque não é mil maravilhas como a gente acha que vai ser. [...] então procurei mesmo participar de tudo que tinha no posto quando eu tinha tempo, pra saber mesmo e sobre o vínculo principalmente nos primeiros meses.” M9

"Acho importante. Porque quando ela crescer que se tornar uma moça ela vai ter confiança em mim. Porque o amor que a gente constrói agora de pequeno eles levam pra quando ela crescer." M11

"Para que no futuro ele saiba que, ou "eu tando" viva ou não, ele teve uma mãe.” M13

“Se ele reconhecer né, é bom. Porque tem filho que quando cresce não reconhece nada.” M15

"Eu vou dar a ela o que eu sinto, vou dar amor. Não vou esperar isso, não vou criar a minha filha, deixar de viver pra quando ela crescer reconhecer e fazer o mesmo por mim, não! Eu vou dar o melhor de mim pra se no futuro quiser reconhecer bem, se não quiser pelo menos foi criada com carinho.” M17

Diante das percepções ao longo da entrevista, foi possível notar que essa pergunta gerou maior dificuldade nas respostas para a maioria das participantes, algumas não souberam definir ou até mesmo não compreenderam o questionamento a princípio. De modo geral as mães acham importante o vínculo com o bebê para a construção da personalidade da criança e para o reconhecimento quando atingirem a fase adulta. É importante ressaltar as rodas de conversa proporcionadas pela unidade de saúde como forma de fazer educação em saúde a respeito da construção do vínculo e como espaço que permite que as mães se expressem e tirem as suas dúvidas sobre a maternagem.

\subsection{Processo de identificação das necessidades do bebê e a linguagem não verbal}

Durante a entrevista as mães foram questionadas a respeito da interpretação da linguagem do bebê quando o mesmo sinaliza suas necessidades. À vista disso, seguem as falas das participantes perante a pergunta "Como se deu o processo de identificação das necessidades, principalmente através do choro?”:

"Eu ainda tenho dificuldade de identificar quando ele chora, porque ele chora demais, às vezes é até malcriação, mas eu já penso que ele tá sentindo alguma dor, ele é muito malcriado, tudo ele se joga no chão. Quando ele tá com fome eu 
vejo pela barriguinha dele, mas quando é dor eu não consigo saber. Sempre quando ele quer alguma coisa ele aponta, às vezes ele pede. Sempre quando ele está incomodado ele chora, ele me chama ou aponta.” M1

"Quando ela tá com fome começa com a boquinha mastigando, quando quer ficar em pé começa a esticar as pernas, e negócio de dor até agora, graças a Deus, ela não sentiu ainda." M4

“É o mesmo choro sempre, eu fico em dúvida de que é.” M5

"Ele chora muito e eu não consigo perceber se é fome, dor." M6

"Quando ela está me querendo ela chora sem parar. Quando está querendo banho começa com um resmungo. Quando está com dor, ela começa a reclamar e chorar um pouco mais alto. Quando ela quer o peito ela já fica com a linguinha mexendo, quando está incomodada ela começa a passar a mão no rosto e a reclamar mexendo os braços e com um chorinho." M7

"Quando ele está irritado ele chora forte, quando ele quer mamar ele começa a se irritar aos pouquinhos. Aí eu vejo logo, quando ele não tem cocô e nem xixi ele quer o peito. Ou se não pela posição mesmo, uma simples posição, quando ele está incomodado quer ficar no colo ou ficar sentadinho aí eu já sei. É tão incrível isso! Meu esposo não entende, ele acha que tudo é o peito." M9

"Ela chora dois tipos: quando está atrás de mamar e quando está de xixi e de coco. Ela fica meio aperreada com as perninhas, aí eu sei que ela está de xixi ou cocô. E quando está com fome ela chora normal.” M10

Diante das fases do desenvolvimento infantil, o bebê possui uma forma singular de comunicação, através da linguagem subjetiva. Para compreender as demandas, desconfortos e outras necessidades do bebê o binômio precisa de um envolvimento que é imprescindível para a comunicação. Através das falas percebe-se que a maioria das mães conseguem discernir os sinais do bebê como a mãe M9 que descreve com precisão cada sinal do seu filho. A minoria das mães apresentou alguma dificuldade de interpretar a comunicação do bebê.

\subsection{Amamentação}

Cada mãe foi questionada se o seu filho foi amamentado e como se desenvolveu esse processo. Este tópico reúne as falas de algumas participantes acerca da experiência que vivenciaram ou ainda estão vivenciando com o aleitamento materno.

"Nunca mamou. Não consegui dar de mamar. Ele não mamou porque meu peito não tem bico. Na maternidade eu tive que tentar [...] mas eu não consegui. Fiquei tentando em casa porque o povo dizia que se botasse ele pra mamar fazia o bico sozinho, mas não consegui, ficava saindo sangue, ficava ferido. Mas me arrependo. [...] É muito importante amamentar, me arrependo muito de não ter amamentado. Até porque se dá de mamar não precisa comprar o leite que gasta muito." M1

"Foi fácil tirar do peito, tirei com 2 dias. Só que eu não quis dar porque senão ela ia querer ficar só comigo, ia querer mais ninguém." M3

"Amamento com prazer. [...] Ele não quer pegar o bico da mamadeira e meu peito tá sequinho, isso tem me irritado." 
"Estou me sentindo mal porque não estou conseguindo amamentar, ele não pega no peito, chora bastante, eu não consigo dormir." M6

"Eu gosto muito, porque ela fica me olhando muito. Às vezes eu estou assistindo e ela mamando, aí ela fica me olhando esperando que eu converse com ela, porque eu sempre fico falando com ela, aí ela fica esperando sempre que eu converse com ela." M7

"Ele só mamava, mas como voltei a trabalhar eu não consigo tirar o leite, aí tô dando a fórmula enquanto estou no trabalho porque não tenho leite suficiente para ordenhar, só enche quando ele mama. Lá no trabalho eu não tenho como tirar o leite, não tem local, só tem um banheiro.” M9

"Quando ela tá mamando eu esqueço de tudo, é só o peito.” M10

"Eu sempre tive isso comigo de amamentar. É um momento único, aquele olhar sem vergonha dele pra mim é tudo." M13

"Eu até pensei em tirar, mas ele pega não o bico da mamadeira. Às vezes eu acho que o meu leite não tá forte pra ele, que tá pouco." M15

Dentre as 20 participantes, 18 mães responderam que o bebê chegou a ser alimentado exclusivamente no peito, enquanto que 2 mães disseram que não passaram pelo aleitamento materno exclusivo (AME). No entanto, entre as 18 mães, 6 delas interromperam a amamentação exclusiva antes dos 6 meses completos do bebê, considerando a idade do bebê no período da coleta e a resposta da mãe, uma vez que 3 bebês tinham 4 meses, 2 tinham 5 meses e 1 bebê que foi amamentado até o segundo dia de vida. A amamentação é vista sob diversos pontos de vista, desde um momento insubstituível, prazeroso e satisfatório até uma forma de tornar a criança dependente da mãe ao ponto de não ficar com outras pessoas quando for necessário.

\section{Discussão}

A transição que a mulher perpassa ao tornar-se mãe envolve uma nova realidade que exige uma adaptação para assumir uma nova identidade. Ramona Mercer iniciou estudos direcionados para esse processo e definiu a consecução do papel maternal como:

Processo de interação e de desenvolvimento em que a mãe se liga ao seu filho, adquirindo competências nos cuidados ao bebê e exprime sentimentos de satisfação e prazer no desempenho do papel maternal. A identidade materna constituise como a última etapa da consecução do papel maternal, onde a mãe sente harmonia e confiança no desempenho do seu papel (Henriques, 2018, p. 13).

Assim como Mercer definiu o papel maternal, a mesma também enfatizou o cuidado de enfermagem ao considerar o protagonismo da classe desde a gestação até o primeiro ano pós-parto, principalmente, considerando a influência deste processo de transição para o binômio visando a repercussão a longo prazo tanto na mãe quanto no bebê. Além disso, devido ao amplo conhecimento dos enfermeiros da área materno infantil, em especial, desde os cuidados inerentes à díade até as orientações acerca de todo o processo adaptativo para a qualificação da vinculação entre a mãe e o bebê (Henriques, 2018).

O vínculo afetivo entre os pais e o bebê repercute na formação dos laços sociais que serão construídos ao longo do CD da criança. Essa interação gera impacto na saúde física, mental e comportamental, contribuindo para a organização fisiológica do bebê, em resposta aos eventos estressores e às relações sociais. Através dos avanços nas pesquisas que objetivam estudar os 
biomarcadores do vínculo afetivo, descobriu-se o papel da ocitocina nesse processo:

Parece que a ocitocina é fundamental na criação de um vínculo coeso entre pais e filhos que se origina das interações calmantes e reconfortantes que os bebês experimentam durante os primeiros cuidados de vida. Isso ajudou a informar o conceito de que o contato pai-filho é fundamental para o estabelecimento de laços de afiliação. Esses laços são formados por meio de interações sociais sincrônicas (ou recíprocas). Interações síncronas são aquelas em que um pai ou filho respondem um ao outro, as ações e respostas não são predeterminadas e servem como processos de auto-organização a partir das entradas sociais encontradas na interação. O contato dos pais não é apenas crítico para a interação social, mas também para a trajetória de desenvolvimento do bebê (Scatliffe et al, 2019, p. 446).

Algumas atitudes maternas têm tendência a expressar um maior afeto, como o olhar, o toque e a fala. As atitudes do pai diferem no aspecto comportamental mais estimulante e lúdico. Porém um não sobrepõe o outro e tais comportamentos, tanto maternos quanto paternos, propiciam a sincronia social que é a reciprocidade diante das interações entre pais e filhos. A liberação da ocitocina está associada a essa sincronia social, em que há um aumento na ocitocina durante as interações e isso evidencia a importância desse hormônio na construção do apego (Scatliffe et al., 2019).

A figura de apego reverbera no bebê a sensação de segurança, cuidado, amor e outros sentimentos que vão sendo desenvolvidos a partir das suas experiências. Esse processo é desencadeado gradativamente pela troca mútua, pelo envolvimento da díade nas interações vivenciadas no cotidiano. As atitudes do bebê podem ser estimuladas pela mãe a partir do seu olhar em relação ao comportamento do filho, repercutindo diretamente no desenvolvimento cognitivo e social da criança (Arpini et al., 2015).

A qualidade do apego entre mãe e filho provoca resultados relevantes no desenvolvimento da criança, estando estreitamente relacionada ao amadurecimento da habilidade do bebê em se autorregular nos níveis fisiológicos, comportamentais e emocionais. Quanto maior a sensibilidade materna em relação ao bebê, menores os riscos de comprometimentos socioemocionais na criança, garantindo um desenvolvimento saudável e menos vulnerável aos fatores estressores (Behrendt, et al., 2019).

Todas as dimensões exercem influência direta na construção do indivíduo e na formação dos vínculos ao longo da vida. O apego entre mãe e filho é indispensável e recebe os efeitos de vários fatores. A respeito disso, Cavalcante e colaboradores (2017, p. 1684) afirmam que:

Prejuízos na relação mãe-filho dificilmente podem ser explicados mediante análise de um único fator isoladamente, pois as condições de risco tendem a ser multidimensionais, envolvendo, com diferentes intensidades, aspectos socioculturais, biológicos e psicológicos referentes à mãe ou ao bebê (Cavalcante et al., 2017, p. 1684).

O presente estudo obteve como resultado que 11 mães (55\%) tinham até 22 anos de idade e que, dentro dessa faixa etária, 6 delas apresentavam idade entre 14 e 19 anos. Outra variável que merece destaque é que 6 mães planejaram engravidar e 14 mães não planejaram a gravidez.

A gestação não planejada é aquela que não foi programada pela mulher ou pelo casal e que ocorreu fora do momento desejado. O pouco conhecimento a respeito da saúde reprodutiva, do planejamento familiar, o acesso aos métodos contraceptivos e às orientações para o uso adequado são indicadores importantes voltados para o aumento dos números relacionados às gestações não planejadas (Rodrigues, 2016).

Nesse viés, é notória a necessidade de uma reorganização nas estratégias direcionadas ao acompanhamento e às orientações, que ficam a cargo da atenção primária, a respeito da saúde sexual e reprodutiva e sobre o planejamento familiar. Consequentemente, obtém-se um maior alcance do compartilhamento do conhecimento com as mulheres, em especial, sobre os métodos contraceptivos disponibilizados pelo Sistema Único de Saúde (SUS) e suas respectivas formas de utilização, bem como a sua eficácia na redução dos índices de gestações não planejadas e principalmente durante a adolescência, além da prevenção 
das Infecções Sexualmente Transmissíveis (IST's) a depender do método adotado. Assim, torna-se evidente a importância da participação ativa dos profissionais de saúde no rastreamento e na captação das mulheres e no incentivo da participação no planejamento familiar.

Além da não utilização ou do uso de forma errada dos contraceptivos, é preciso considerar que algumas mulheres podem sentir dificuldades em negociar com seus parceiros a utilização do preservativo ou de outros métodos contraceptivos.

O planejamento da gravidez assume um papel crucial entre os fatores que influenciam a construção adequada do vínculo entre o binômio mãe-bebê. Vivenciar a gestação não planejada oferece riscos que podem comprometer o estabelecimento do vínculo, estando associado também a possibilidade de rejeição da criança. No entanto, algumas mães perpassam pelo processo de aceitação e que sobrepõe o sentimento de rejeição, passando a lidar com sua nova fase e se permitindo interagir com o bebê (Cavalcante et al., 2017).

Neste estudo, embora 14 mães não tenham planejado a gravidez, nenhuma referiu rejeição ao bebê e permanecem com seus respectivos filhos.

De acordo com o art. $2^{\circ}$ do Estatuto da Criança e do Adolescente (ECA), para efeitos da Lei 8.069, de 13/07/1990, é considerado adolescente o indivíduo que se enquadra na faixa etária dos 12 aos 18 anos de idade. A Organização Mundial de Saúde (OMS) classifica a fase da adolescência entre 10 e 19 anos de idade (Brasil, 1990; Senna \& Dessen, 2015). Conforme esses parâmetros foi possível observar que o presente estudo obteve 6 mães que engravidaram durante a adolescência.

A gravidez na adolescência exprime a carência ainda maior de um apoio à figura materna. $\mathrm{O}$ apoio social auxilia no desempenho materno, gerando mais confiança na mãe e mais conhecimento acerca do desenvolvimento da criança. Diniz, Santos $\&$ Koller (2017, p. 282) definem o apoio social conforme o texto a seguir:

O apoio social é uma variável essencial para a maternidade, principalmente na adolescência. O apoio social é definido como um conjunto de relações formais e informais que proporcionam ajuda emocional, material e / ou instrumental quando alguém precisa enfrentar situações que geram algum tipo de tensão emocional. [...] A falta de apoio social é identificada como uma das maiores dificuldades que os adolescentes enfrentam durante a gravidez ou parentalidade (Diniz; Santos \& Koller, 2017, p. 282).

Diante disso, é preciso direcionar a atenção a essas mães adolescentes como forma de incentivar e auxiliar na transição para o papel materno, principalmente emocionalmente, instruindo acerca dos cuidados durante a gravidez e o pós-parto para que ela consiga cuidar adequadamente do bebê e oferecer os estímulos que ele irá precisar para crescer e se desenvolver. Considerando os riscos do nascimento prematuro em gestantes adolescentes, é indispensável o acompanhamento para evitar os atrasos no desenvolvimento infantil e prevenir possíveis agravos à saúde da criança que também geram impactos no meio familiar.

Ao associar a qualidade do vínculo entre as mães adolescentes com seus bebês, Wilson e seus colaboradores (2017, p. 512-513) afirmam que:

As mães adolescentes em geral são menos interativas, menos positivas em seu estilo parental e têm mais dificuldades em resolver problemas e em comportamentos parentais mais severos. As crianças nascidas de mães adolescentes correm maior risco de atrasos no desenvolvimento, déficits no desenvolvimento cognitivo e social e problemas comportamentais. [...] Há evidências de que as mães adolescentes exibem estilos de apego mais inseguros do que as mães adultas (Wilson et al., 2017, p. 512-513).

A partir das observações durante as entrevistas foi possível perceber que algumas mães adolescentes se relacionavam satisfatoriamente com seus bebês e cuidavam da melhor forma possível. Enquanto algumas mães adultas relataram sentir dificuldades, às vezes, de identificar alguma necessidade no bebê ou até mesmo sentir dificuldade em cuidar da criança sozinha. 
As atitudes que unem a mãe ao seu bebê são indispensáveis para que eles se conheçam e para que compreendam suas necessidades. Segurar o bebê no colo para amamentar, a troca de olhares, a responsividade diante do comportamento do bebê como forma de dar atenção são exemplos de condutas que fortalecem o elo entre a díade.

A Organização Mundial de Saúde e o Ministério da Saúde recomendam o aleitamento materno (AM) de modo exclusivo nos primeiros seis meses de vida, após esse período deve-se introduzir a alimentação complementar juntamente com a manutenção do AM até os dois anos de idade (Brasil, 2015; Valente \& Osterne, 2015).

O risco de mortalidade é reduzido em até 14 vezes para os bebês que passam pelo AME quando comparados com os bebês que não são amamentados. Porém, apenas $41 \%$ são amamentados exclusivamente nos primeiros seis meses de vida, índice que os Estados Membros da OMS precisam se empenhar para atingir, ao menos, 50\% até o ano de 2025 (Organização PanAmericana da Saúde, 2020).

O aleitamento materno vai além da função nutritiva e imunológica, permitindo um envolvimento entre a díade mãebebê, uma vez que é um momento que inclui apenas o binômio. $\mathrm{O}$ ato de segurar o bebê no colo, a troca mútua de olhares e a sucção eficaz contribuem para o fortalecimento do elo materno infantil e para a manutenção da amamentação. Além disso, todo esse contato íntimo auxilia a mãe a se ligar ao bebê e compreender as suas necessidades (Silva \& Braga, 2019).

Logo após o nascimento é essencial favorecer o contato pele a pele entre a mãe e o bebê. Entre os recursos adquiridos destacam-se o controle térmico, reduzindo risco de hipotermia, além de ser um momento oportuno para iniciar a amamentação e reduzir o risco de hipoglicemia. Com isso ocorre o estímulo para a descida do leite e esse início precoce do AM contribui para a manutenção e o prolongamento do aleitamento materno exclusivo.

A literatura demonstra que algumas razões podem comprometer o aleitamento materno e favorecer o desmame precoce. O estudo desenvolvido por Conceição \& Fernandes (2015, p. 601) evidencia que:

Os pesquisadores têm procurado identificar os fatores que dificultam ou impedem a prática do AM e entre os motivos mais alegados pelas mães, destacam-se a "figuração" do leite fraco ou escasso, traumas mamilares, falta de experiência e de apoio, trabalho fora do lar, o querer e o poder amamentar. Outra situação que interfere na manutenção do AM e, provavelmente, reduz sua duração é a gravidez não planejada. Entretanto, este fator é pouco evidenciado nas publicações. [...] Mães que programaram a gestação mantêm o aleitamento por mais tempo (Conceição \& Fernandes, 2015, p. 601).

Outras possíveis causas do desmame precoce incluem a falta de apoio e incentivo dos profissionais de saúde, a mídia através das propagandas das fórmulas infantis, o uso de chupetas, falta de paciência e persistência da mãe. As primíparas, em especial, podem sentir determinadas dificuldades nos primeiros dias da amamentação. Valente \& Osterne (2015) apresentaram em seus resultados a importância dada pelas mães a respeito das visitas domiciliares pelos profissionais da Estratégia de Saúde da Família (ESF). As mães alegaram que, se as visitas tivessem sido mais frequentes no puerpério haveria uma chance maior de prosseguirem com AME, considerando a relevância do acompanhamento para intervir nas demandas e dificuldades maternas (Valente \& Osterne, 2015).

Entre os fatores que dificultam o aleitamento materno, algumas mães compartilharam experiências semelhantes ao encontrado na citação supracitada ao referir que o bebê não foi amamentado pelas condições anatômicas mamilares e por traumas mamilares ou mesmo por escolha própria justificando que a criança não iria ficar com outros cuidadores quando necessário.

As motivações para o início, a manutenção e a interrupção da amamentação variam entre cada mãe e pode envolver experiências já vivenciadas, padrões sociais, culturais e estéticos, a relação conjugal e o incentivo do companheiro, além da falta de conhecimento sobre os benefícios valiosos oferecidos pelo leite materno. Além dessas razões, o acompanhamento de qualidade no pré-natal também exerce influência na manutenção da amamentação, visto que as gestantes devem ser instruídas e tirar dúvidas referentes ao ciclo gravídico, principalmente a respeito da amamentação. 
O trabalho fora do lar também configura um fator a ser considerado entre as causas para a interrupção do aleitamento materno. Uma participante do estudo trabalha fora de casa e, por esse motivo, precisou inserir a fórmula láctea infantil na alimentação do seu bebê alegando não conseguir ordenhar no trabalho devido à falta de um ambiente adequado. Mesmo diante da dificuldade, a mãe se alegrou ao falar que o bebê não esqueceu o peito e ao chegar em casa ela consegue amamentar.

Ao relacionar o vínculo empregatício com a manutenção do aleitamento materno, Conceição \& Fernandes (2015, p. 602) mencionam em seu estudo que:

Não ter emprego remunerado permitiria à mãe permanecer mais tempo ao lado do filho e manter por mais tempo o AME. Alguns autores indicam o trabalho da mulher fora do lar como um obstáculo ao AM, porque nem todas as empresas liberam a licença maternidade por seis meses (Conceição \& Fernandes, 2015, p. 602).

Um estudo australiano a respeito dos determinantes do aleitamento materno contínuo aos 12 e 24 meses fez comparações entre variáveis para obter os possíveis fatores que interferem na continuidade da amamentação. Alguns fatores apresentaram significância, dentre os quais destacam-se as características sociodemográficas e a relação com a paridade. Em países de alta renda o nível de escolaridade materna esteve altamente relacionado com a continuação da amamentação, destacando que quanto maior o grau de instrução maior a probabilidade de amamentar aos 12 meses (Scott et al., 2019).

A paridade foi independentemente associada à continuação da amamentação, em que as mulheres multíparas têm 52\% mais chances de amamentar aos 12 meses em relação às primíparas. As mulheres australianas tinham uma tendência maior a amamentar o segundo filho por um período mínimo de 6 meses se houvessem amamentado o primeiro filho durante 6 meses, ressaltando a importância de auxiliar as mulheres primíparas no estabelecimento do aleitamento materno como forma de garantir a sua manutenção e os benefícios para a saúde materno infantil (Scott et al., 2019).

Outros estudos apontam que as mulheres que receberam o apoio do parceiro para amamentar tinham $76 \%$ mais chances de permanecer amamentando até os 12 meses em comparação aos parceiros que preferiam a introdução da fórmula ou eram ambivalentes aos métodos de alimentação (AM e fórmula). $\mathrm{O}$ apoio do parceiro mostrou-se fortemente associado à decisão de amamentar e continuar amamentando (Conceição \& Fernandes, 2015; Scott et al., 2019).

Assim como os inúmeros fatores, mencionados ao longo do texto, exercem influência no vínculo entre o binômio, Reichert e seus colaboradores (2017) discutem que a relação construída entre o profissional e a rede familiar é excepcional para a continuidade do cuidado à criança. Quanto maior for a aproximação entre ambos, melhor será a adesão da família ao acompanhamento infantil com a unidade de saúde.

$\mathrm{O}$ estudo concluiu que o cuidado deve abranger a criança e seu contexto familiar para que os mesmos se sintam como parte integrante do processo. Proporcionar um ambiente agradável, transmitir confiança, promover a escuta qualificada, prestar uma assistência sem distinções, sanar as dúvidas e ser resolutivo foram pontos mencionados pelas mães como importantes durante a consulta, favorecendo a busca pela prevenção da saúde e não somente quando surgirem sinais e sintomas na criança (Reichert et al., 2017).

Entre as limitações do estudo destacou-se a dificuldade de comunicação, principalmente com as mães adolescentes, visto que suas falas eram, em sua maioria, monossilábicas, gerando um obstáculo para a extração dos dados e as observações pertinentes à pesquisa.

\section{Conclusão}

A presente pesquisa tornou possível investigar os aspectos que contribuem ou prejudicam a criação dos laços afetivos, tendo como principais atuantes neste processo a mãe e o bebê.

Através dos resultados obtidos destacaram-se a gravidez na adolescência; a sobrecarga materna em virtude das 
atividades domésticas juntamente com os cuidados prestados ao bebê, explicitando a importância da rede de apoio; a dificuldade para interpretar a linguagem subjetiva da criança e os sinais de desconforto emitidos pelo bebê; e a amamentação.

Portanto, é preciso conhecer os fatores que conferem risco à díade e considerar as especificidades de cada relação a fim de frear os possíveis danos que resultam em um vínculo não consolidado e que reflete diretamente no processo de construção do indivíduo.

Considerando que os profissionais da saúde da atenção primária acompanham as mães desde o pré-natal, é imprescindível preparar a mulher durante todo o ciclo gravídico, contribuindo para a qualificação do apego, o conhecimento da mãe acerca dos cuidados inerentes ao bebê, incluindo a importância do aleitamento materno exclusivo.

Em suma, faz-se necessário o investimento em estudos que demonstrem a relevância da interação entre a mãe e o bebê, assim como os reflexos que esse vínculo promove no crescimento e desenvolvimento da criança. Além disso, a importância da atuação dos profissionais de enfermagem no acompanhamento e nas orientações capazes de reduzir os índices desde as gestações não planejadas até os riscos que comprometem a saúde materno infantil.

\section{Referências}

Almeida, A. P. De, Ceballo, L. de C., Barbosa, A. R. C., Nogueira, D. A., \& Moreira, D. da S. (2017). O registro do crescimento e desenvolvimento da criança na caderneta de saúde. Revista Enfermagem UERJ, 25(0), 10-15. http://dx.doi.org/10.12957/reuerj.2017.16895

Arpini, D. M., Zanatta, E., Marchesan, R. Q., Savegnago, S. D. O., \& Bernardi, P. H. (2015). Intervenções precoces na infância: observando a relação mãe-bebê em um serviço de saúde. Psicologia em Revista, 21(1), 37. https://doi.org/10.5752/p.1678-9523.2015v21n1p37

Behrendt, H. F., Scharke, W., Herpertz-Dahlmann, B., Konrad, K., \& Firk, C. (2019). Like mother, like child? Maternal determinants of children's early socialemotional development. Infant Mental Health Journal, 40(2), 234-247. https://doi.org/10.1002/imhj.21765

Brasil, Ministério da Saúde. (2012). Saúde da criança: crescimento e desenvolvimento. In Cadernos de Atenção Básica N. 33. http://bvsms.saude.gov.br/bvs/publicacoes/saude_crianca_crescimento_desenvolvimento.pdf.

Brasil, Ministério da Saúde. (2018). Política Nacional de Atenção Integral à Saúde da Criança: orientações para implementação. https://portaldeboaspraticas.iff.fiocruz.br/wp-content/uploads/2018/07/Pol\%C3\%ADtica-Nacional-de-Aten\%C3\%A7\%C3\%A3o-Integral-\%C3\%A0-

Sa\%C3\%BAde-da-Crian\%C3\%A7a-PNAISC-Vers\%C3\%A3o-Eletr\%C3\%B4nica.pdf.

Brasil, Ministério da Saúde. (2018). Saúde da criança: aleitamento materno e alimentação complementar. In Cadernos de Atenção Básica N. 23. https://bvsms.saude.gov.br/bvs/publicacoes/saude_crianca_aleitamento_materno_cab23.pdf

Brasil. Presidência da República. Lei 8.069, de 13 de Julho de 1990 . Estatuto da Criança e do Adolescente. http://www.planalto.gov.br/ccivil_03/LEIS/L8069.htm .

Câmara, R. H. (2013). Análise de conteúdo: da teoria à prática em pesquisas sociais aplicadas às organizações. Revista Interinstitucional de Psicologia, 6(2), 179-191. http://pepsic.bvsalud.org/pdf/gerais/v6n2/v6n2a03.pdf

Cavalcante, M. C. V., Filho, F. L., França, A. K. T. da C., \& Lamy, Z. C. (2017). Relação mãe-filho e fatores associados: Análise hierarquizada de base populacional em uma capital do Brasil-Estudo BRISA. Ciência e Saúde Coletiva, 22(5), 1683-1693. https://doi.org/10.1590/1413-81232017225.21722015

Conceição, S. P. da, \& Fernandes, R. A. Q. (2015). Influência da gravidez não planejada no tempo de aleitamento materno. Escola Anna Nery - Revista de Enfermagem, 19(4), 600-605. https://doi.org/10.5935/1414-8145.20150080

Diniz, E., Santos, L. de S. dos, \& Koller, S. H. (2017). Social support as moderator of knowledge about infant development in adolescent mothers. Paidéia, 28(68), 281-289. https://doi.org/10.1590/1982-43272768201705

Fontanella, B. J. B., Ricas, J., \& Turato, E. R. (2008). Amostragem por saturação em pesquisas qualitativas em saúde: contribuições teóricas. Cadernos de Saúde Pública, 24(1), 17-27. https://doi.org/10.1590/s0102-311x2008000100003

Gaiva, M. A. M., Monteschio, C. A. C., Moreira, M. D. de S., \& Salge, A. K. M. (2018). Avaliação do crescimento e desenvolvimento infantil na consulta de enfermagem. Revista. Avances en. Enfermería, 36(1), 9-21. http://www.scielo.org.co/pdf/aven/v36n1/0121-4500-aven-36-01-00009.pdf.

Henriques, C. M. G. (2018). Transição para o papel maternal: a experiência vivida de mulheres com problemas de adição a substâncias psicoativas. https://repositorio.ul.pt/bitstream/10451/33134/1/ulsd731592_td_Carolina_Henriques.pdf

Lima, L., Nobre, C., Lopes, A. C., Rolim, K., Albuquerque, C., \& Araújo, M. A. (2016). A Utilização da Caderneta de Saúde da Criança no acompanhamento Infantil. Revista Brasileira de Ciências da Saúde, 20(2), 167-174. https://doi.org/10.4034/rbcs.2016.20.02.12

Marciano, R. P., \& Amaral, W. N. (2015). Vínculo mãe-bebê da gestação ao pós-parto uma revisão sistemática de artigos empíricos publicados na língua portuguesa. Femina, 43(4), 155-159. https://pesquisa.bvsalud.org/portal/resource/pt/lil-771206?lang=en . 
Neves, K. da R., Morais, R. L. de S., Teixeira, R. A., \& Pinto, P. A. F. (2016). Growth and development and their environmental and biological determinants. Jornal de Pediatria, 92(3), 241-250. https://www.sciencedirect.com/science/article/pii/S2255553616000045?via\%3Dihub .

Oliveira, A. de. (2016). Avaliação do laço mãe e bebê: elaboração e construção de instrumento e estudos de evidência de validade. https://repositorio.ufrn.br/jspui/bitstream/123456789/21776/1/AdrianaDeOliveira_TESE_unprotected.pdf

Oliveira, T. M. V. de. (2001). Amostragem não Probabilística: Adequação de Situações para uso e Limitações de amostras por Conveniência, Julgamento e Quotas. Administração On Line, 2(3), 1-7. https://pesquisa-eaesp.fgv.br/sites/gvpesquisa.fgv.br/files/arquivos/veludo__amostragem_nao_probabilistica_adequacao_de_situacoes_para_uso_e_limitacoes_de_amostras_por_conveniencia.pdf .

Organização Pan-Americana da Saúde. Organização Mundial De Saúde. (2020). Países estão falhando em impedir comercialização prejudicial de sub stitutos do leite materno, alertam OMS e UNICEF. https://www.paho.org/bra/index.php?option=com_content\&view=article\&id=6182:paises-estao-falhando-em-impedircomercializacao-prejudicial-de-substitutos-do-leite-materno-alertam-oms-e-unicef\&Itemid=839 .

Reichert, A. P. da S., Rodrigues, P. F., Cruz, T. M. A. V., Dias, T. K. C., Tacla, M. T. G. M., \& Collet, N. (2017). Percepção de mães sobre o vínculo com enfermeiros na consulta à criança. Revista de Enfermagem UFPE on Line, 11(2), 483-490. https://doi.org/10.5205/reuol.10263-91568-1-RV.1102201701

Ribeiro, C. M., Mendes, L. R., Couto, D. P. do, \& Azevedo, J. M. de. (2017). Homoparentalidade: reflexões sobre a constitu ição psíquica da criança adotada. Estilos da Clínica, 22(3), 522-539. https://doi.org/10.11606/issn.1981-1624.v22i3p1-18

Rodrigues, C. D. D. S., \& Lopes, A. O. S. (2016). A Gravidez não planejada de mulheres atendidas no pré-natal das Unidades Básicas de Saúde. Revista Multidisciplinar e de Psicologia, 10(32), 70. https://doi.org/10.14295/idonline.v10i32.579

Rosa, J. M., Melo, A. K., Boris, G. D. J. B., \& Santos, M. A. dos. (2016). A Construção dos Papéis Parentais em Casais Homoafetivos Adotantes. Psicologia: Ciência e Profissão, 36(1), 210-223. https://doi.org/10.1590/1982-3703001132014

Santos, A. da S., Brito, L. L. M. de S., Pessoa, V. L. M. de P., Monteiro, A. R. M., Guimarães, J. M. X., \& Chaves, E. M. C. (2017). Teoria da consecução do papel materno para tornar-se mãe de recém-nascido prematuro. RETEP - Revista Tendência da Enfermagem Profissional, 9(4), 2311-2314. http://www.corence.org.br/wp-content/uploads/2019/02/TEORIA-DA-CONSECU\%C3\%87\%C3\%83O-DO-PAPEL-MATERNO-PARA-TORNAR-SE-M\%C3\%83E.pdf

Scatliffe, N., Casavant, S., Vittner, D., \& Cong, X. (2019). Oxytocin and early parent-infant interactions: A systematic review. International Journal of Nursing Sciences, 6(4), 445-453. https://doi.org/10.1016/j.jijnss.2019.09.009

Scott, J., Ahwong, E., Devenish, G., Ha, D., \& Do, L. (2019). Determinants of continued breastfeeding at 12 and 24 months: Re sults of an Australian cohort study. International Journal of Environmental Research and Public Health, 16(20). https://doi.org/10.3390/ijerph16203980

Senna, S. R. C. M., \& Maria Auxiliadora Dessen. (2015). Reflexões sobre a saúde do adolescente brasileiro. Psicologia, Saúde \& Doenças, 16(2), 217-229. http://www.scielo.mec.pt/scielo.php?script=sci_arttext\&pid=S1645-00862015000200008\&lng=pt\&nrm=iso

Silva, B. A. A. da, \& Braga, L. P. (2019). Fatores promotores do vínculo mãe-bebê no puerpério imediato hospitalar: uma revisão integrativa. Revista. SBPH, 22(1), 258-279. http://pepsic.bvsalud.org/scielo.php?script=sci_arttext\&pid=S1516-08582019000100014\&lng=pt\&nrm=iso

Valente, M. de F. F., \& Osterne, M. do S. F. (2014). A efetividade das políticas de incentivo ao aleitamento materno em combate ao desmame precoce: um estudo realizado com as mães de crianças atendidas na unidade de puericultura do CPN. Conhecer: debate entre o público e o privado, 12, 98-125. $\mathrm{http} / / /$ seer.uece.br/?journal=politicaspublicasemdebate\&page $=$ article\&op=view\&path\%5B $\% 5 \mathrm{D}=1302$

Wilson, D., Gross, D., Hodgkinson, S., \& Deater-Deckard, K. (2017). Association of teen mothers' and grandmothers' parenting capacities with child development: A study protocol. Research in Nursing and Health, 40(6), 512-518. https://doi.org/10.1002/nur.21839 